\title{
The phonology of sign languages
}

\section{INTRODUCTION}

Compared to spoken language phonology, the field of sign language phonology is a young one, having begun in the 1960s together with research into sign languages generally. Before this point, linguists often dismissed the academic study of sign languages as manual representations of spoken languages (e.g., Bloomfield, 1933) or as iconic wholes lacking any internal structure. However, since Stokoe's (1960) seminal work, sign language linguists have demonstrated that, as with spoken languages, sign languages have sub-lexical structure that is systematically organised and constrained. In addition though, sign languages also stand in stark contrast to spoken languages because they are produced in the visual-gestural modality and therefore the articulators involved in phonological organisation are different. Within this chapter, we provide an introduction to the field of sign language phonology and a selective overview of contributions to date. We also highlight key areas that have attracted much debate amongst sign language linguists such as the development of phonological models, the effect of modality on phonology, and the relationship between sign language and gesture. In Section 4, we describe new contributions to the field which have the potential to further illuminate our understanding of sign language phonology in the future. Our description will be centred around two unrelated sign languages: American Sign Language (ASL) and British Sign Language (BSL), though many of the patterns here have been described for other sign languages as well. This chapter's concluding note emphasises that in order to understand phonology, one must consider sign languages.

\section{DEFINITIONS}

In this section, we briefly outline sign language phonology and key terms that have been used to refer to the organisation of signs at this level of the language.

\subsection{The sign language lexicon}

Sign language interaction is made up of different types of signs. These different types have been exemplified in models of the sign language lexicon proposed by many 
Fenlon, J., Cormier, K., \& Brentari, D. (in press). The phonology of sign languages. In S. J. Hannahs \& A. Bosch (Eds.), The Routledge Handbook of Phonological Theory: Routledge.

researchers (e.g., Johnston and Schembri, 1999, Brentari and Padden, 2001, Cormier et al., 2012); see Figure 1 for such a model adapted from Brentari and Padden (2001).

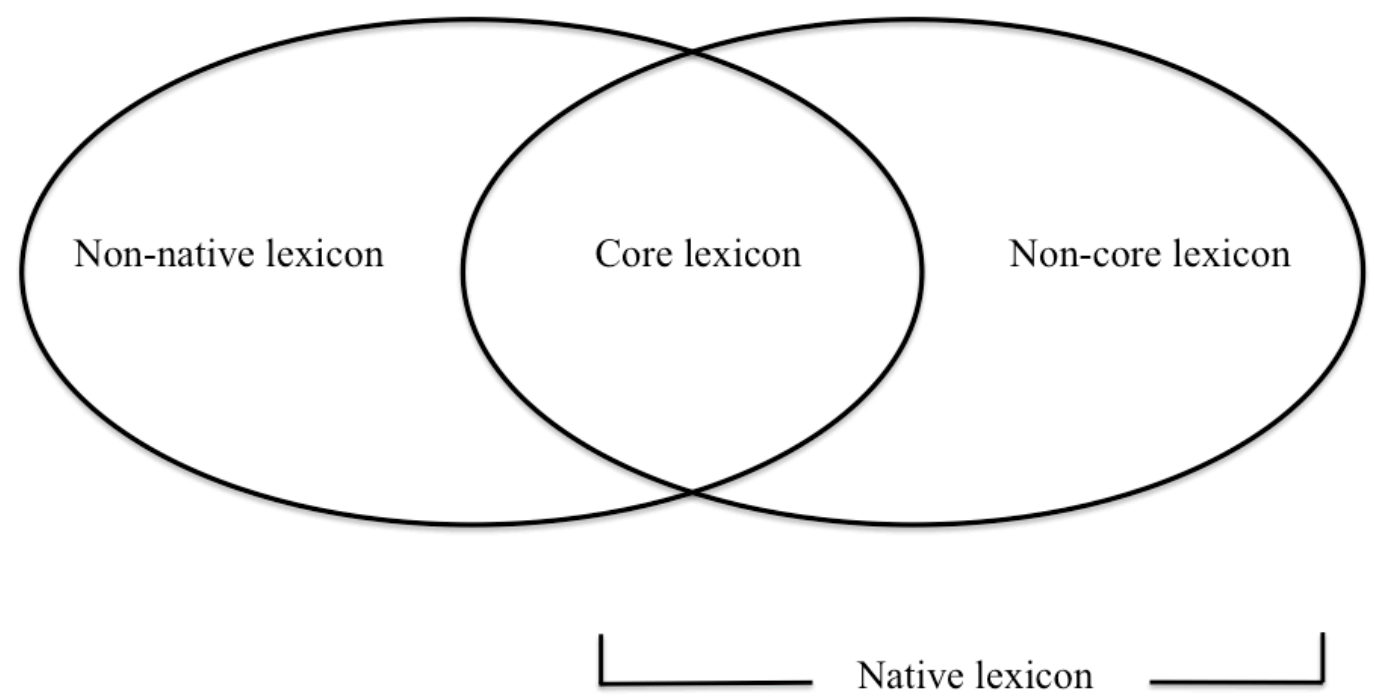

Figure 1: Sign language lexicon (adapted from Brentari and Padden, 2001)

Here the lexicon is divided into the following components: the core lexicon, the noncore lexicon, and the non-native lexicon. Signs in the core lexicon are described as being comprised of meaningless sublexical units with a highly conventionalised form and meaning association; these are the signs you would typically expect to see listed in a sign language dictionary. Much of the work on phonological theory concerning sign languages has been based on this component of the lexicon. Signs from the noncore lexicon are, in contrast, made up of meaningful units and typically refer to socalled classifier constructions or signs involving sequences of constructed action (Cormier et al., 2012). Finally, the non-native lexicon refers to fingerspelled sequences. Fingerspelled sequences represent a form of borrowing where different configurations of the hand are each associated with a letter from the corresponding spoken language's alphabet in order to spell out a word. Importantly, signs from the non-core and the non-native lexicon differ in their structural properties from signs in the core lexicon in terms of handshape inventories as well as in the application of phonological constraints and rules (Eccarius, 2008). In the following section, we describe how signs are organised at the phonological level focusing on the core lexicon. We refer to signs from other components of the lexicon in Section 3.3 when 
Fenlon, J., Cormier, K., \& Brentari, D. (in press). The phonology of sign languages. In S. J. Hannahs \& A. Bosch (Eds.), The Routledge Handbook of Phonological Theory: Routledge.

we consider the relationship between signs from the non-core lexicon and gesture, a prominent and current area of enquiry.

\subsection{The core lexicon: The phonological architecture of the sign}

It is widely acknowledged in the sign language literature that the parameters of handshape, place of articulation 'POA' (or location), movement, and orientation play a significant role at the phonological level in a similar way to the spoken language properties of place of articulation, manner and voicing. In the BSL sign DANGER, the parameters specified are: the $\mathrm{W}$ hand for handshape, the ipsilateral side of the forehead for place of articulation, and a short repeated movement contacting the forehead for movement. Orientation, which is interpreted here as the relationship between the active hand and the place of articulation, is the radial side of the hand (i.e., the part of the hand that contacts the place of articulation). Justification for the feature units within each parameter stem from their ability to show contrasts. For example, the BSL sign GAY differs from BSL UNSURE along the handshape dimension alone (BSL GAY has only an extended thumb with all fingers closed whilst BSL UNSURE has an extended thumb with all fingers extended). In Figure 2, pairs of contrasts along each parameter in BSL are provided.

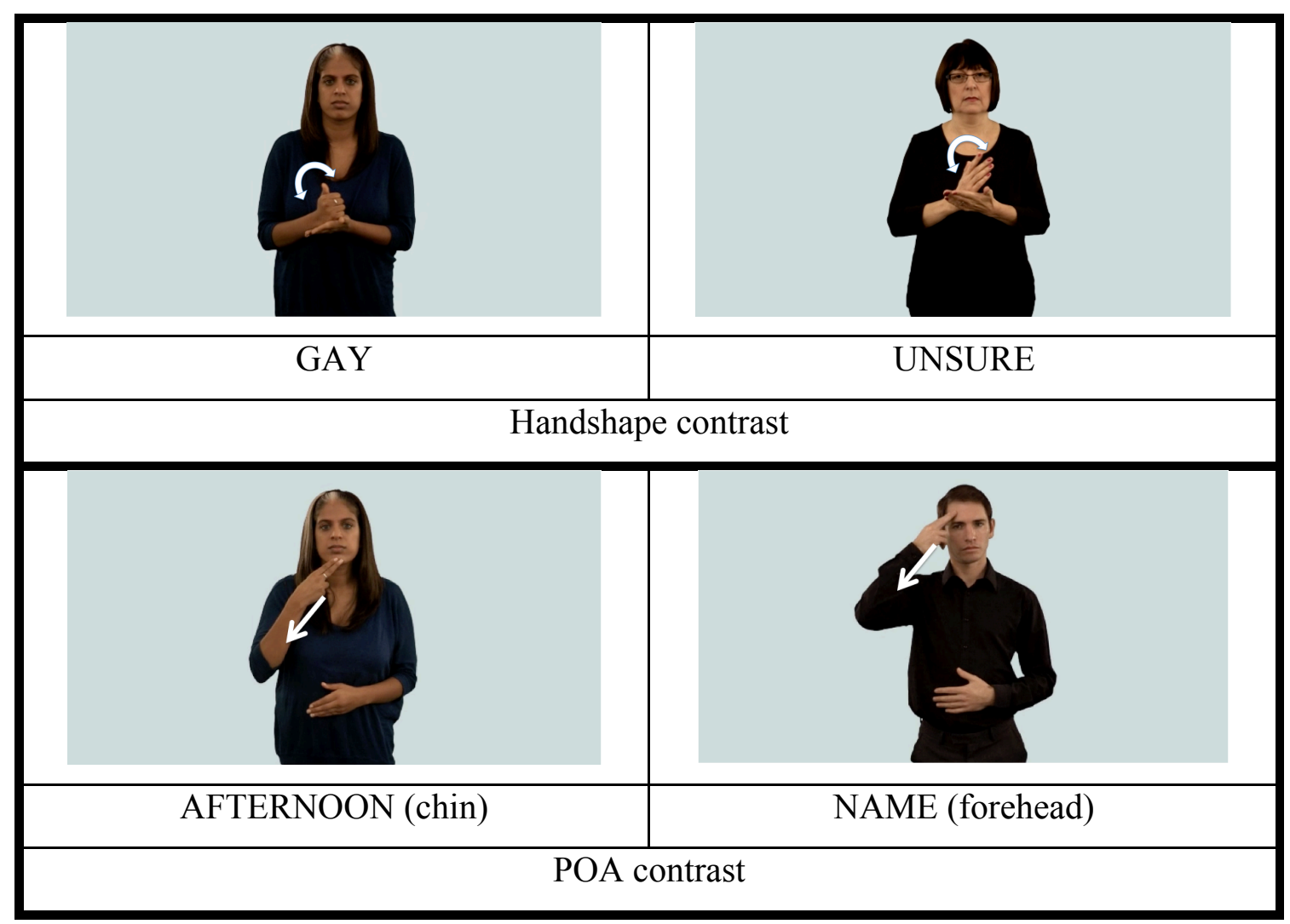




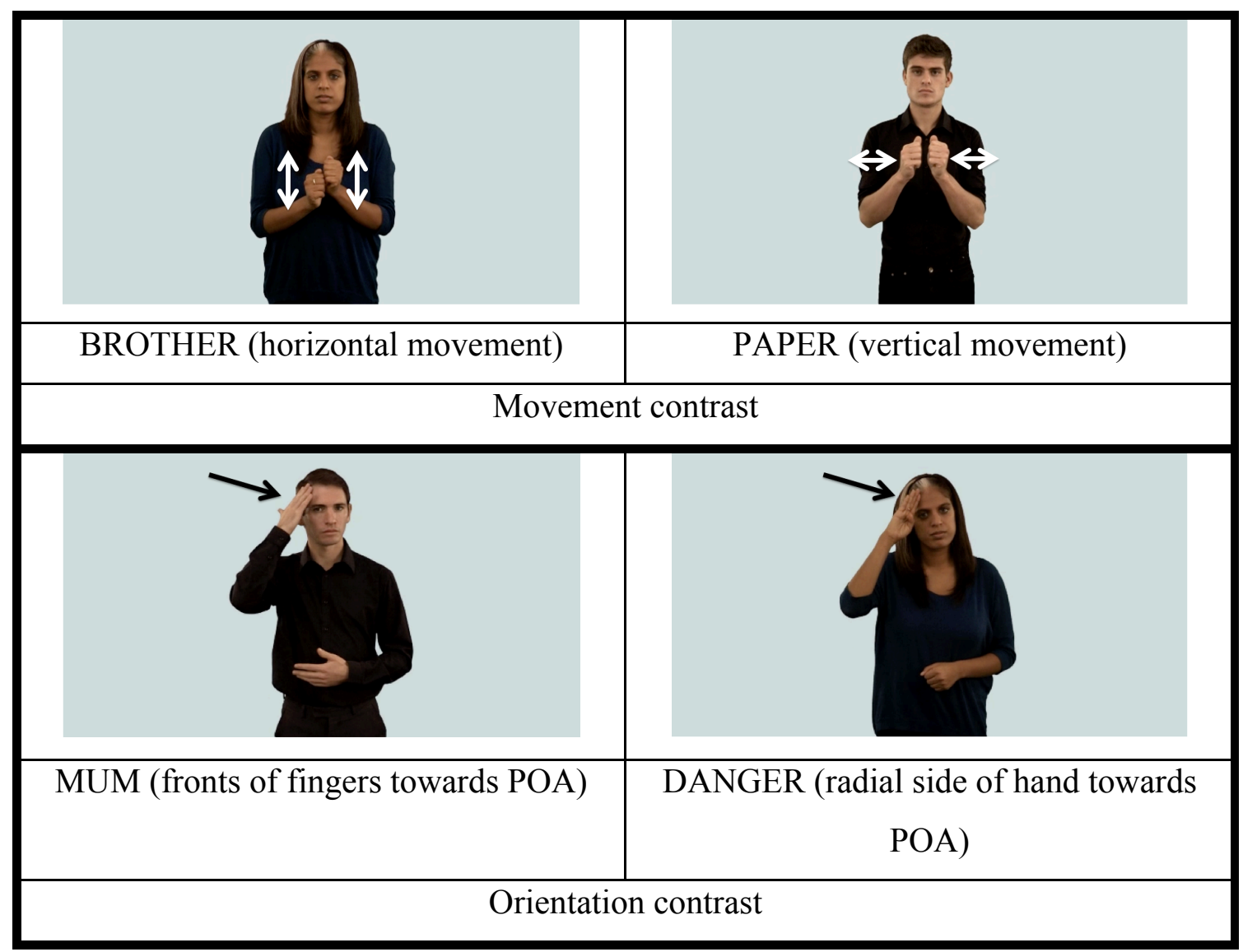

Figure 2: Sign pairs with handshape, location movement and orientation contrasts in BSL

Within the core lexicon, the parameters of handshape, location, movement, and orientation are typically viewed as meaningless sublexical elements (e.g., there appears to be no iconic motivation for the handshape in the signs PAPER or DANGER; these are arbitrary sub-lexical elements that are contrastive in BSL). Several phonological models have been proposed to account for a sign's underlying representation and the organisation of these parameters. Within this section, an overview of the general organisation of the sign according to the Prosodic Model is provided (see Figure 3). We refer again to other phonological models in Section 3.1. 
Fenlon, J., Cormier, K., \& Brentari, D. (in press). The phonology of sign languages. In S. J. Hannahs \& A. Bosch (Eds.), The Routledge Handbook of Phonological Theory: Routledge.

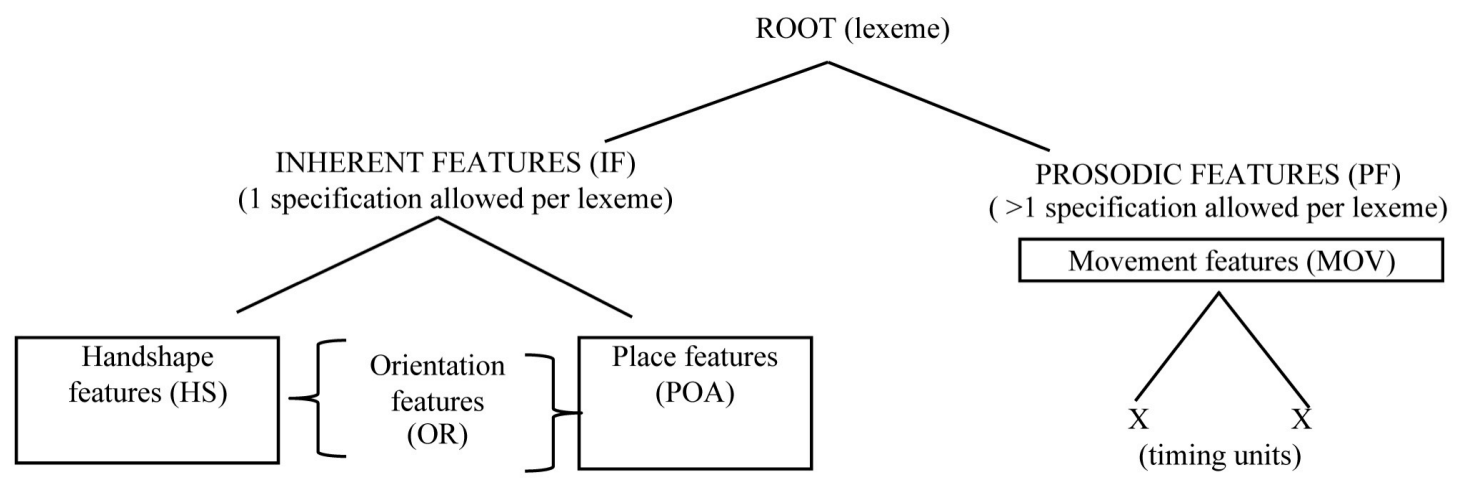

Figure 3: Overview of the Prosodic Model

The Prosodic Model follows Dependency Theory (Anderson and Ewen, 1987, van der Hulst, 1993) in that each node is maximally binary branching, and each branching structure has a head (which is more elaborate) and a dependent (which is less elaborate). In the following sub-sections, we describe how the parameters of handshape, POA, orientation, movement are represented within the Prosodic Model. These sub-sections will refer briefly to the class nodes of the feature hierarchy.

\subsection{The core lexicon: Inherent Features}

A closer look at the Inherent Features structure within the Prosodic Model is provided in Figure 4. The Inherent Features structure branches into the parameters of handshape and place of articulation (Location or POA); each will be discussed in turn. 


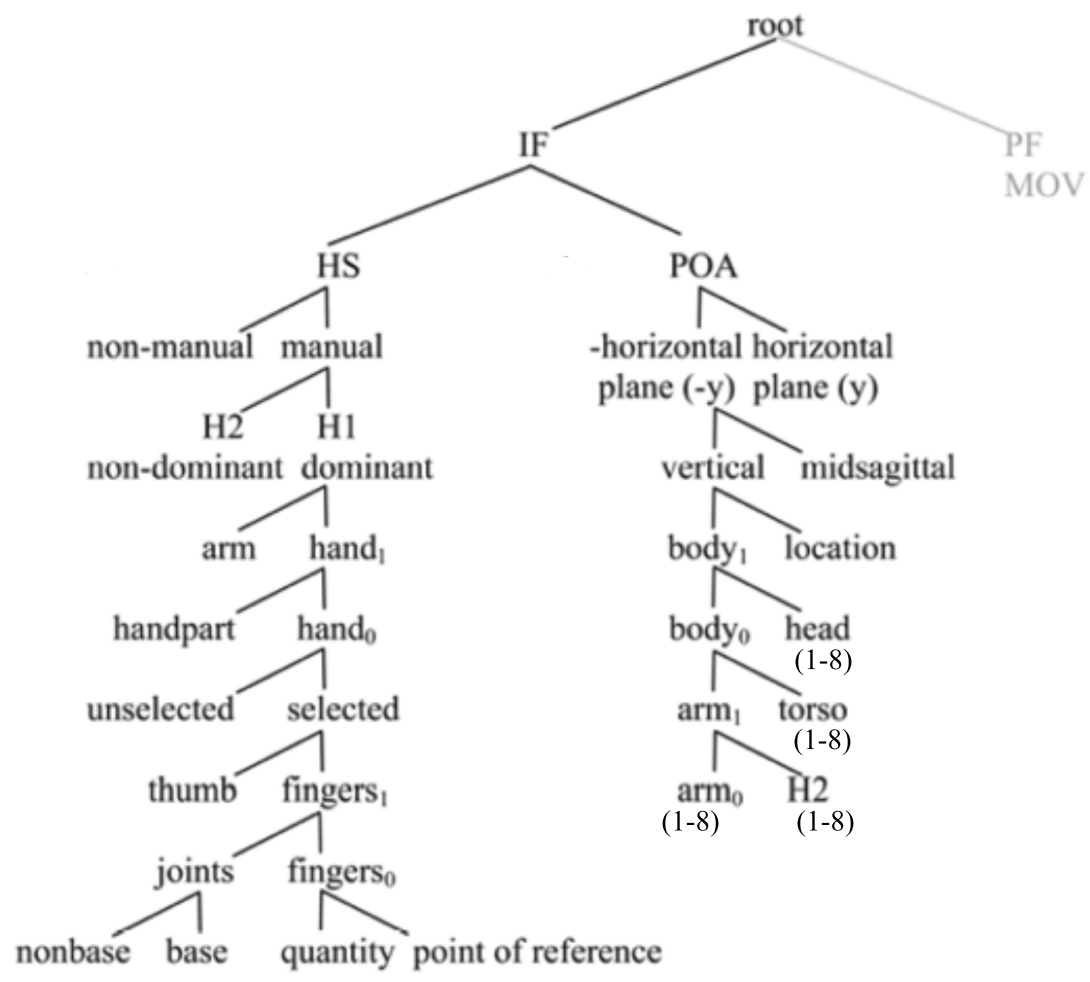

Figure 4: Inherent Features Structure

\subsubsection{Handshape}

The handshape parameter is specified within the Inherent Features structure. Beginning at the top-most node, the active articulator is first specified which is typically the arms and hands. In some cases, a sign may only use non-manual articulators (e.g., the head, the face, and/or the body) but these types of signs are relatively rare in signed languages. The manual node then branches into the dominant (H1) and non-dominant (H2) hands. If the sign is two-handed, it will have both $\mathrm{H} 1$ and $\mathrm{H} 2$ features. If the sign is one-handed, it will only have $\mathrm{H} 1$ features. These features include which fingers are 'active' (selected), how many are selected (quantity), and whether they are straight, bent, flat or curved (joints). It is at this level (i.e., the feature) that the minimal units of contrast can be identified. For example, BSL GAY and BSL UNSURE in Figure 2 differ according to features of selected fingers: GAY is specified only for the thumb (i.e., no finger features), whilst UNSURE is specified for the thumb and [all] fingers.

\subsubsection{Place of Articulation (POA)}

As with handshape, POA is represented within the Inherent Features structure. Its organisation within the Prosodic Model reflects the generalisation that there are four 
Fenlon, J., Cormier, K., \& Brentari, D. (in press). The phonology of sign languages. In S. J. Hannahs \& A. Bosch (Eds.), The Routledge Handbook of Phonological Theory: Routledge.

major body regions (the body, the head, the torso, and the arm) and that each region has eight place distinctions. Beginning from the POA branch within the Inherent Features structure, the passive articulator is specified. This is divided into threedimensional planes - horizontal (y-plane), vertical (x-plane), and mid-sagittal (zplane). Signs occurring along the vertical plane may also be specified for one of the major locations on the body: the head, the torso, the arm, or the non-dominant hand. Within each of the eight major locations, eight further POA values are specified. For example, the eight POA values for the head, which are thought to be contrastive in ASL are: top of the head, forehead, eye, cheek/nose, upper lip, mouth, chin, under the chin. The model predicts that there will be eight distinctions in each of the major locations, but the values may well be language particular, differing from sign language to sign language.

\subsubsection{Orientation}

Orientation is traditionally regarded as a minor parameter since there are fewer minimal pairs based on orientation alone (Brentari, 2012). Earlier descriptions of orientation (e.g., Stokoe et al., 1965, Battison, 1978) were often based on the direction of the palm and the fingertips (e.g., in BSL TRUE, the palm is facing leftwards and the fingertips are facing forwards). Within the Prosodic Model, as well as Crasborn and van der Kooij (1997) for Sign Language of the Netherlands (NGT), orientation is regarded as being derived from a relationship between an active handpart and the POA. From this perspective, the orientation in BSL TRUE would be expressed as the relation between the ulnar side of the dominant hand (i.e., handpart) towards the palm of the non-dominant hand (i.e., the POA).

\subsection{The core lexicon: Prosodic Features}

Returning to Figure 3, one can see that the root lexeme branches into both Inherent Features and Prosodic Features. Figure 5 provides a detailed representation of the organisation of the Prosodic Features tree. 


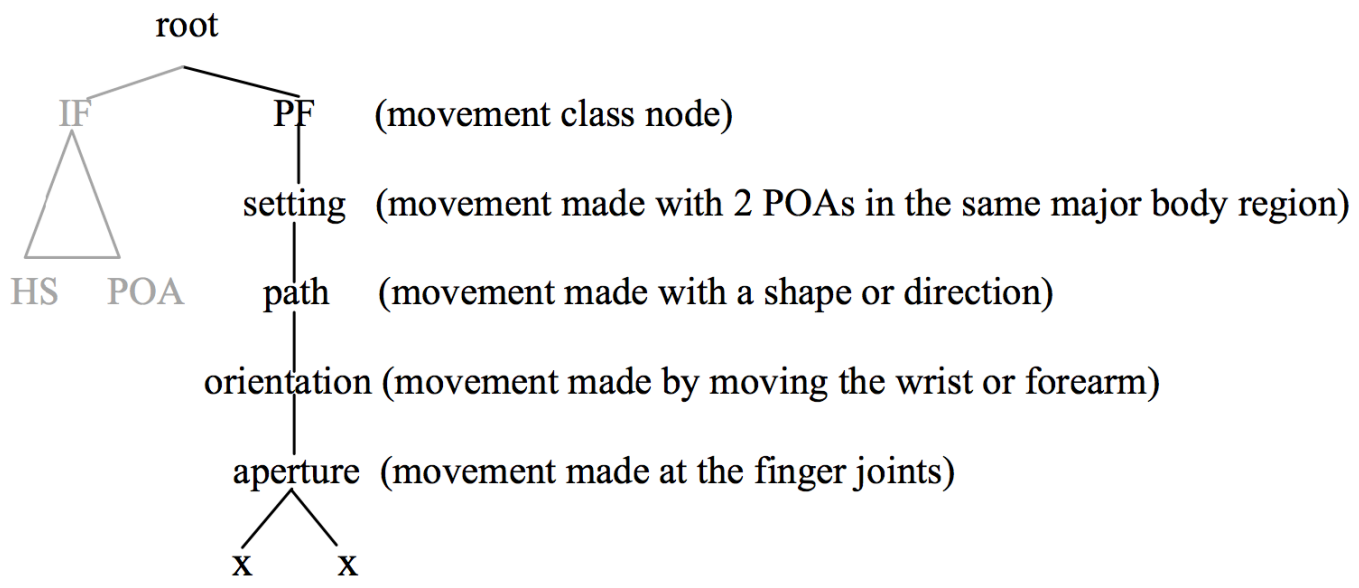

Figure 5: Prosodic Features representation within the Prosodic Model

Within the Prosodic Features structure of the Prosodic Model, the dynamic elements of signs are specified. These dynamic elements contrast with handshape and POA within the Inherent Features branch since, by their very nature, they are features that can change within a sign. Additionally, it is within the Prosodic Features branch that segmental (or timing units) structure is derived. A major motivation in this separation lies in the fact that Prosodic Features are realised sequentially whilst Inherent Features are realised simultaneously. In addition, the hierarchical structure within the Prosodic Features branch is not as complex when compared to the organisation of Inherent Features.

\subsubsection{Movement}

Movements are dynamic acts with a trajectory, a beginning, and an end; their phonological representation will vary depending on the body part used to articulate the movement (see Figure 6). The movement change in ASL UNDERSTAND is a change in aperture that is articulated by the finger joints. The movement change in ASL HAPPEN is a change in orientation articulated by the radial-ulnar (forearm) joint. Furthermore, it is the elbow that articulates a path movement in ASL SEE and the shoulder that articulates a setting movement in ASL WE. Body parts involved in the articulation of movement are organised within the Prosodic Model beginning with 
the more proximal joints (e.g., the shoulder) and ending with the more distal joints (e.g., the fingers). In some signs, it is also possible to have two simultaneous types of movements articulated together. For example, ASL HAPPEN can also be produced with both the radial-ulnar joint and movement from the shoulder joint resulting in a downward movement. Other signs like ASL THROW have both a path movement and what is known as a secondary movement (i.e., aperture change within the hand) (Sandler and Lillo-Martin, 2006). The different types of movements as they would be represented within the Prosodic Model are also provided in Figure 6.

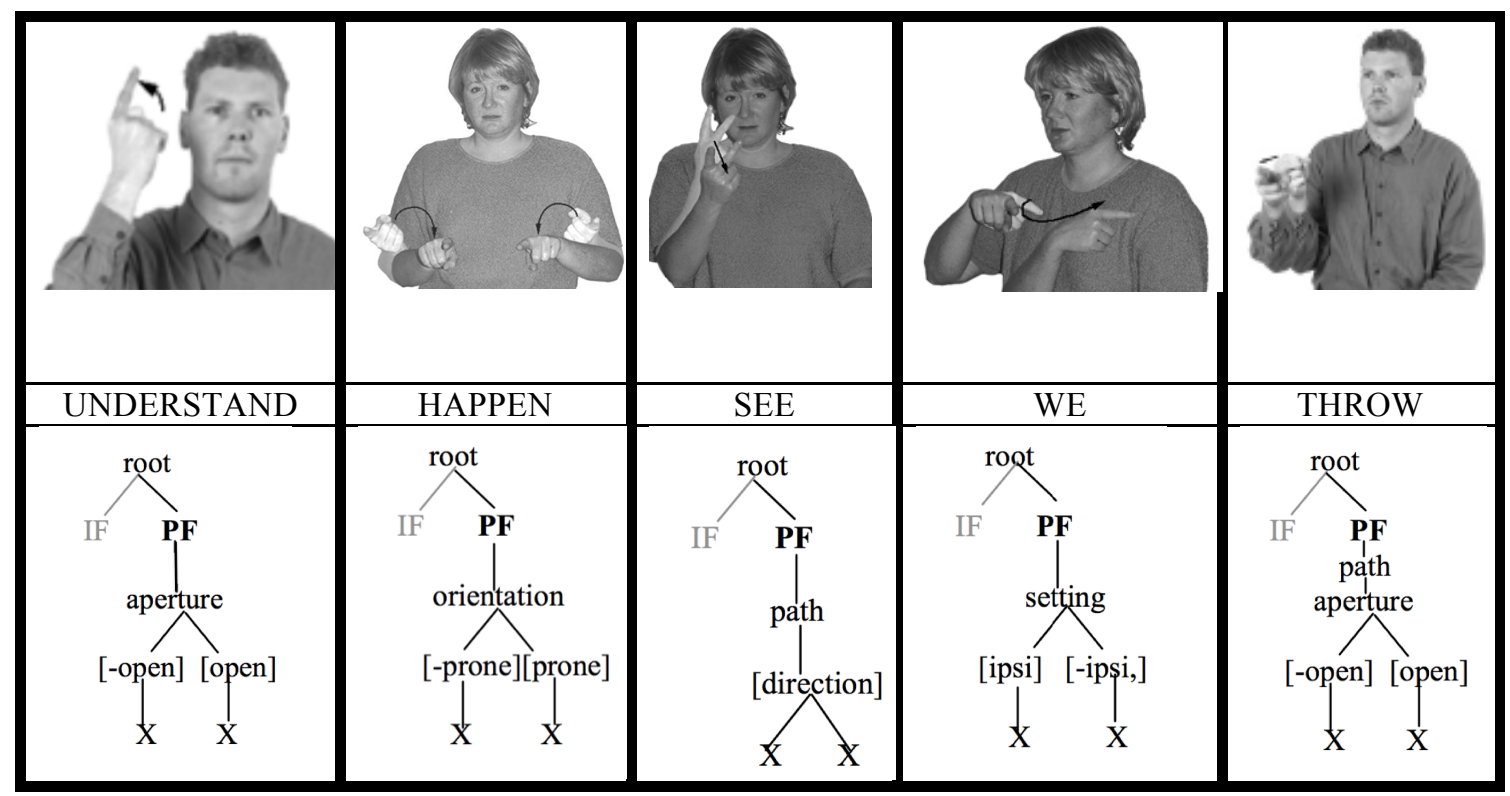

Figure 6: Different types of movement in ASL and as represented within the Prosodic Model

Whilst much has been made of the simultaneous nature of sign languages, it is uncontroversial (as noted above) that signs are comprised of sequential elements. This sequentiality is represented through timing slots projected within the prosodic structure (shown as X-slots in Figure). Path features generate two timing slots; all other features generate one timing slot. Inherent Features do not generate timing slots at all; only movement features do this within the Prosodic Model. When two movement components are articulated simultaneously as in ASL THROW, they align with one another and only two timing slots are projected onto the timing tier (see ASL THROW in Figure 6). Timing slots typically do not create minimal pairs (i.e., duration is not contrastive in sign languages) but play an important role in describing where morphological modifications appear. For instance, when a sign is modified for 
Fenlon, J., Cormier, K., \& Brentari, D. (in press). The phonology of sign languages. In S. J. Hannahs \& A. Bosch (Eds.), The Routledge Handbook of Phonological Theory: Routledge.

intensity in both ASL and BSL, the first segment is lengthened (e.g., BSL QUICK can be held in its initial position during its articulation resulting in the overall meaning of 'very quick').

\subsection{Phonological units in sign language}

In our brief description of the parameters recognised as playing a role in the phonology of sign languages, one can see that parallels can be made with phonological units attested in spoken language. A parameter in sign languages constitutes a fundamental group of features, similar to possible segment types in spoken languages (e.g., vowels, glides, obstruents, approximants). A group of features is often referred to as a "major class" in general phonological theory, specifically in feature geometry-e.g., 'laryngeal' or 'dorsal' are feature classes in spoken languages, and are at the same level as 'joints' or 'selected fingers' within the handshape parameter. Consequently, features such [+flexed] and [-flexed] have the same relation to the 'joints' feature class in a sign language as [spread glottis] has to the 'laryngeal' class in a spoken language. These features, as in spoken language phonology, are the smallest units and the minimal properties that can create a minimal pair.

Movement features also play an important role in the sign language syllable with movement being described as analogous to vowels. Parallels between the two can be seen when one considers that vowels and movements are perceptually the most salient feature within a word or a sign and that movement is what makes signs visible, just as vowels make words audible. In fact, researchers have proposed that more visually salient movements are more sonorous - that is, wiggling the fingers is less sonorant than twisting of the radial/ulnar joint (forearm), which is less sonorous than a path movement (Sandler, 1993, Corina, 1990, Brentari, 1993, Perlmutter, 1992). The criteria for counting syllables in sign languages are outlined below.

Syllable Counting Criteria: The number of syllables in a sequence of signs equals the number of sequential movements in that string

\begin{tabular}{l|l} 
a. & When several shorter (e.g., secondary) movements co-occur with a single
\end{tabular} (e.g., path) movement of longer duration, the longer movement is the one to which the syllable refers 
Fenlon, J., Cormier, K., \& Brentari, D. (in press). The phonology of sign languages. In S. J. Hannahs \& A. Bosch (Eds.), The Routledge Handbook of Phonological Theory: Routledge.

\begin{tabular}{|l|l|}
\hline b. & $\begin{array}{l}\text { When two or more movements occur at exactly the same time, it counts as } \\
\text { one syllable, e.g., ASL THROW is one syllable containing an aperture } \\
\text { change and a path movement. }\end{array}$ \\
\hline
\end{tabular}

Figure 7: Syllable Counting Criteria (Brentari, 1998)

Several arguments can be made to demonstrate that movement plays a central organising role at the phonological level forming a unit similar to the syllable nucleus in spoken languages. Firstly, fingerspelled letters or number signs produced in stasis have been observed to add an epenthetic movement in some sign languages when used as an independent word (Brentari, 1990, Jantunen, 2007, Geraci, 2009). Brentari (1990) suggests that, as in spoken languages where an operation of vowel epenthesis ensures syllable well-formedeness, movement is inserted where necessary to ensure that the signed output is a well-formed syllable. Secondly, the repetition of movement appears as a rhythmic sequential unit produced by deaf infants at a similar milestone to vocal babbling observed in hearing children (Pettito and Marentette, 1991). Thirdly, morphological modifications to signs are often permitted on the basis of their movement properties. Signs containing one movement element are permitted to undergo modifications that result in derived nominal forms (e.g., the path movement in ASL SIT can be repeated to derive the nominal form CHAIR) in contrast to signs consisting of two or more movements such as ASL THROW (which contains both a path and secondary movement). This suggests that forms allowing reduplication have one simultaneous movement component and are light syllables whilst those that disallow reduplication have two or more simultaneous movement elements and are therefore heavy. This also demonstrates that sign syllables do not have the same internal structure as spoken languages syllables - i.e., syllable weight and sonority are not related in this way in spoken languages.

Lastly, it should be noted that the parameters specified (i.e., handshape, POA and movement) all combine to form a lexeme at the root node in contrast to spoken languages where they would combine to form a vowel or consonant like unit. As mentioned above, this demonstrates that features in sign languages are typically specified only once per lexeme, not once per segment or once per syllable, but once per word. This is a fact that is - if not explicitly stated - implied in many models of 
Fenlon, J., Cormier, K., \& Brentari, D. (in press). The phonology of sign languages. In S. J. Hannahs \& A. Bosch (Eds.), The Routledge Handbook of Phonological Theory: Routledge.

sign language phonology. Whilst parallels can be drawn with tone in tonal languages and features that harmonise across a lexeme (e.g., vowels), it appears that fewer features in speech are associated with the domain of the word in spoken languages than in signed languages; this points to a fundamental difference between signed and spoken language phonology. Importantly, all sign languages that have been subject to serious inquiry have been noted to operate in this way; the extent to which tone and vowel harmony are attested cross-linguistically for spoken languages does not approach a similar scale by comparison.

\section{CRITICAL ISSUES AND TOPICS}

In this section, we underline three areas of interest within the field of sign language phonology. These are: the development of phonological models/phonological theory, the effect of modality on phonological organisation, and the link between sign language and gestures produced by non-signers at the phonological level. The third area is one that has received particular interest from sign language linguists in recent years.

\subsection{Phonological models}

Different phonological models have been proposed to account for the underlying representation of signs. These can be understood with reference to the history of phonological theory generally. The earliest model of sign language phonology proposed by Stokoe (1960) emphasised the simultaneous nature of signs (i.e., the parameters of handshape, location, and movement are all realised at the same time in production) and made no attempt at defining these parameters according to a hierarchy. Instead, like spoken language models in the 1950s, Stokoe (1960) focused on providing evidence for the feature units using phonemic contrast (as explained above). Later models made the important observation that signs could also be comprised of sequential segments (or timing units). Beginning with Liddell and Johnson's (1989) Hold-Movement Model, a sign was divided into linear segments described as either 'holds' or 'movements' at the centre of its representation. Within each segment, a number of articulatory features could be identified although these features did not appear to enter into a hierarchical relationship with one another. Liddell and Johnson's model can be said to mirror Chomsky and Halle (1968) Sound Patterns of English which was biased towards a sequential representation of segments. 
Fenlon, J., Cormier, K., \& Brentari, D. (in press). The phonology of sign languages. In S. J. Hannahs \& A. Bosch (Eds.), The Routledge Handbook of Phonological Theory: Routledge.

Liddell and Johnson drew parallels between spoken and signed languages by likening holds (i.e., static elements) to consonants and movements (i.e., dynamic elements) to vowels. However, as features were individually associated within each segment, the Hold-Movement Model contained a substantial amount of redundant information (e.g., for the BSL sign NAME as shown in Figure 2, the same handshape would be specified across segments despite there being no change in this parameter). As spoken language models became increasingly non-linear, the Hand Tier Model (Sandler, 1989), the Prosodic Model (Brentari, 1998), and the Dependency Model (van der Kooij, 2002), would unite both the sequential and simultaneous nature of signs in their respective representations. These models used feature geometry to hierarchically organise a sign's parameters according to their phonological behaviour and articulatory properties. The Hand Tier Model would first address the shortcomings of the Hold-Movement model by representing handshape as an autosegment. Although linear sequential segments continued to occupy a central role in this model, the simultaneous nature of the sign was also acknowledged. In contrast, later models such as the Prosodic Model and the Dependency Model (van der Hulst, 1993) both placed the simultaneous structure back in central position. Although they differ in some details, both models suggested that segmental structure, despite playing an important role in phonology, is derived from the features specified within a sign. Within the Dependency Model, segmental structure is linked to handshape and POA and movement is given a minor role within the representation since van der Hulst argued that movement could be derived from handshape and POA features. In contrast, the Prosodic Model acknowledged that handshape, place of articulation, and movement all have autosegmental properties but inherent and prosodic elements were placed on separate branches, and it is within the latter branch that segmental structure is derived.

Focusing on recent models that have adopted a featural and autosegmental perspective within their representations (e.g., the Hand Tier Model, the Prosodic Model and the Dependency Model), we can see that there is much consensus across representations despite their differences. For example, there is a tendency for features within the parameters of handshape and POA to be specified once per lexeme. For handshape, this generalisation is captured by the Selected Fingers Constraint (Mandel, 1981, Brentari, 1998) (or the Handshape Sequence Constraint in the Hand Tier model (Sandler, 1989)) which specifies that a sign only has one set of selected fingers within 
Fenlon, J., Cormier, K., \& Brentari, D. (in press). The phonology of sign languages. In S. J. Hannahs \& A. Bosch (Eds.), The Routledge Handbook of Phonological Theory: Routledge.

its articulation; note that ASL THROW, despite having a handshape change, has the same number of selected (or extended) fingers at the beginning and end of its articulation. However, there are important differences between these models that pose interesting questions for further research within the field. These differences point to conflicting ideas regarding the underlying role of a particular articulator or aspect within a phonological representation and highlight areas for further research.

One example is the role of the non-dominant hand in phonological models. Although both hands are often active in connected signing, linguists typically refer to one hand as the primary articulator (or the dominant hand) and the other as the passive articulator (or the non-dominant hand), and distinguish between three types of 2 handed signs (Battison, 1978). In Type 1 signs both hands share the same handshape and movement - they are symmetrical (e.g. BSL PAPER and BROTHER in Figure 2 ); in Type 2 signs both hands share the same handshape, but not the same movement - one hand is held stationary (e.g., BSL UNSURE in Figure 2); and in Type 3 signs the hands share neither the handshape nor the movement - again, one hand is held stationary (e.g., BSL GAY in Figure 2). Each phonological model varies in its treatment of the non-dominant hand within its representation. For the Hand Tier Model, the non-dominant hand has a dual role as a POA in Type $2 \& 3$ signs and as an active articulator in Type 1 signs. In contrast, within the Prosodic Model and the Dependency Model, the two functions are united and the non-dominant hand is represented as having a dependent role (see Figure 4 where H2 occupies the dependent branch of the manual node of the Prosodic Model) within their representations. This captures the fact that the degree of complexity on $\mathrm{H} 2$ is severely constrained, an observation made by Battison (1978) when he formalised the Symmetry and Dominance Constraints. That is, the non-dominant hand is either specified for the same handshape and movement as the dominant hand (the Symmetry Constraint) or if the non-dominant hand is stationary, the handshapes we can expect to see on this hand is restricted to a limited set (the Dominance Constraint).

Additionally, the role of non-manual features (e.g., face and body) within phonological models is unclear. Non-manual features are frequently cited in the literature as a significant parameter in addition to parameters involving the hands. Within the Prosodic Model, non-manual features are represented within the Inherent 
Fenlon, J., Cormier, K., \& Brentari, D. (in press). The phonology of sign languages. In S. J. Hannahs \& A. Bosch (Eds.), The Routledge Handbook of Phonological Theory: Routledge.

Features branch in the top-most node of the Handshape structure (see Figure 4). Signs can be articulated using non-manual features alone and pairs of signs (featuring a manual component) can be contrastive along the non-manual dimension. For example, the ASL signs LATE and NOT-YET differ only in the presence of tongue protrusion in the latter. However, it should be noted that non-manual signs are extremely infrequent when compared to manual signs and very few minimal pairs exist along this dimension. In addition, non-manual features, such as the eyebrows, appear to play an important role at the suprasegmental level and have been likened to intonation in spoken languages (Nespor and Sandler, 1999, Sandler and Lillo-Martin, 2006). These markers also appear to play a role in morphology and syntax (e.g., Neidle et al., 2000, Zeshan, 2004). Given their minor role at the phonological and lexical levels and their other roles in morphology, syntax and discourse, it is unclear how non-manual features should be represented within phonological models. Indeed, current models proposed for sign languages often lack an adequate representation for this parameter.

Another area where models differ is in the representation of the movement parameter. The Prosodic Model ascribes a central role in the phonology to movements. The structure in Figure 5 captures not only the phonological features of movement, it also provides a coherent backbone for the syllable and foundation for higher order prosodic structure. There is widespread agreement that movement plays a key role in syllable structure with regard to its functional similarity to vowels and to syllable nuclei, as well as in higher order prosodic structure - for example, the phenomenon of phrase-final lengthening in Intonational Phrases. But some models have tried to avoid representing movement as a major parameter, and instead derive the movement from the locations and orientations of the start and end of the syllable, with some additional features for manner and repetition (Uyechi, 1995, Channon, 2002, Channon and van der Hulst, 2011).

Finally, it should be noted that although minimal pairs can be found for most parameters in ASL and BSL, it is difficult in many cases to identify minimal pairs for every purported phonological value (i.e. every handshape, location, movement, or orientation) that has been argued to be contrastive within these languages. The only exhaustive attempt to do this for any sign language that we know of is Johnston (1989) for Auslan (Australian Sign Language). More evidence is needed about lexical 
Fenlon, J., Cormier, K., \& Brentari, D. (in press). The phonology of sign languages. In S. J. Hannahs \& A. Bosch (Eds.), The Routledge Handbook of Phonological Theory: Routledge.

contrast in ASL and BSL before claims about particular contrastive units can be confirmed. In the meantime, it has been proposed that phonetic structures, including features, should be judged to be phonologically relevant if they i) create a minimal pair ii) are involved in a phonological rule, or iii) if they are morphological.

\subsection{Modality}

The second issue we discuss here concerns the effect of modality on phonological organisation. The articulators involved in speaking and signing are different; the articulators in speech are the lips, teeth, tongue, throat, and larynx and the articulators in signing are the hands, arms, head, body and face. As outlined by Meier (2002), Meier (2012), there are fundamental differences between these sets of articulators. Firstly, the primary articulators involved in sign languages are paired; there are two hands and arms involved in articulation whilst there is only a single articulator involved in speaking. As phonology is the level of the language that directly interfaces with the articulators, anatomical differences, in turn, have the potential to influence the phonological structure of languages across modalities. It has been proposed that the organisation of a syllable in speech stems from the opening and closing movement of the jaw which acts as an oscillator in speech (MacNeilage, 2008, MacNeilage and Davis, 1993). When one looks at sign languages, it is apparent that there is not a single oscillator linked to articulation. Signs can be produced by different joints within the arms and the hands. On this basis, Meier (2012), Meier (2002) concludes that the syllable in sign language is physically distinct from the syllable in spoken languages since it clearly has a more varied articulatory basis.

The fact that these larger articulators have an effect on production is evidenced by the rate at which words or signs are produced. Studies have reported that the rate of signing appears to be much slower when compared to speaking (Klima and Bellugi, 1979, Grosjean, 1977). In a study by Bellugi and Fischer (1972), the rate of signing measured as signs per second - was twice as long as the rate of speaking - measured as words per second. This difference in production may be attributed to the size of the articulators as the arms and hands are much larger and therefore require more effort to move than those involved in speaking (e.g., the jaw and the tongue). Despite the slower rate of signing compared to speech, however, Bellugi and Fischer found that the proposition rate was similar across signed and spoken languages. They 
Fenlon, J., Cormier, K., \& Brentari, D. (in press). The phonology of sign languages. In S. J. Hannahs \& A. Bosch (Eds.), The Routledge Handbook of Phonological Theory: Routledge.

attributed this to the use of simultaneous organisation in sign languages, concluding that both modalities are equally efficient at conveying information, but do so in different ways.

There are also differences in perception (Brentari, 2002). In audition, humans can temporally resolve auditory stimuli when they are separated by an interval of only 2 milliseconds (Green, 1971, Kohlrausch et al., 1992) whilst the visual system is much slower and requires at least 20 milliseconds to resolve visual stimuli presented sequentially (Chase and Jenner, 1993). The advantage of temporal processing therefore goes to audition. In contrast, simultaneous processing benefits vision over audition. The effect of the speed of light transmission on the perception of objects is that vision can take advantage of light waves reflected from the target object together with secondary reflection from other objects in the environment onto the target object (i.e., visual 'echo' waves). The combination of the two, perceived simultaneously, enhances the three-dimensional quality of the target object (Bregman, 1990) and allows a three-dimensional image to be perceived quickly due to properties of the signal (the same echo phenomenon in audition is much slower). Given these differences in perception across modalities, one might expect words in signed and spoken languages to exploit the advantages available to their respective systems.

One outcome of this basic design of the auditory and visual physiological system is the effect on word shape. Sign languages have a strong tendency towards being monosyllabic. In Stokoe et al. (1965), 83\% of the lexical entries are composed of single sequential movements (using the syllable counting criteria in Figure 7). Evidence for this tendency towards monosyllabicity can also be seen in compounds and nativised fingerspelled signs (i.e., fingerspelled sequences that move from the non-native lexicon to the core lexicon over time, thus taking on phonological characteristics of signs from the core lexicon). This monosyllabic nature is retained even when signs are meaningfully modified in a number of ways (i.e., these modifications are typically feature-sized and simultaneously layered onto the stem). This patterning between meaningful elements and phonological structure represents a substantial difference between sign languages and spoken languages. Whilst spoken languages do have simultaneous phenomena in phonology and morphophonology such as tone, vowel harmony, nasal harmony, and ablaut marking (e.g., the past 
Fenlon, J., Cormier, K., \& Brentari, D. (in press). The phonology of sign languages. In S. J. Hannahs \& A. Bosch (Eds.), The Routledge Handbook of Phonological Theory: Routledge.

preterite in English - sing/sang; ring/rang), this does not approach the scale of simultaneity seen in signed languages. This pattern demonstrates that signal processing differences in the visual and auditory system clearly have an effect on language typology across modalities.

Modality can also have an effect on the distribution of phonological features. In sign languages, the addressee must look at the person signing to them. Since visual acuity is greater toward the central vision area than in the peripheral areas, we might expect an effect on the distribution of features. This appears to be the case for both ASL and BSL, regarding the distribution of marked and unmarked handshapes. In both Battison (1978) for ASL and BSL SignBank (Fenlon et al., 2014) for BSL, when examining signs produced on the body, signs with a marked handshape (i.e., handshapes which are less salient and more difficult to perceive quickly) were much more likely to be produced in the head and neck locations over the trunk and arm locations. For example, in BSL, out of a possible 376 signs using a marked handshape, 286 (76\%) are produced on the head and neck locations where visual acuity is greatest). Similarly, one-handed signs (e.g. BSL NAME as in Figure 2) are much more likely to occur in the head and neck locations over Type 1 two-handed signs (e.g. BSL PAPER as in Figure 2). Additionally, 81.7\% (517/633) of BSL signs produced in the head and neck locations are one handed compared to $59.9 \%$ (169/282) of signs produced in the trunk and arm locations. Siple (1978) suggests that, in conditions of lower acuity, more redundancy may be present in the signal. For Type 1 two-handed signs produced on the trunk, having both hands behave in an identical fashion in the periphery of the addressee's vision means there is more information available to the addressee to identify the sign. This observation, together with the distribution of marked and unmarked handshapes with respect to location, suggests that the constraints imposed on the distribution of features have their origins in perception as suggested by Siple (1978) and Battison (1978).

To sum up, one might therefore expect words in signed and spoken languages to exploit the advantages available to their respective systems. As phonology is the level of the grammar that has a direct link with the perceptual and articulatory phonetic systems, whether visual-gestural or auditory-vocal, we might expect to see differences emerge between the two types of languages in their organisation of phonological 
Fenlon, J., Cormier, K., \& Brentari, D. (in press). The phonology of sign languages. In S. J. Hannahs \& A. Bosch (Eds.), The Routledge Handbook of Phonological Theory: Routledge.

elements. This allows us to question to what extent we can see phonological patterns that are similar across the two modalities and to what extent they are different. These findings have implications for the understanding of phonological theory in general.

\subsection{Sign language and gesture}

One of the most debated issues in sign language phonology (indeed in sign language linguistics generally) is the relationship between sign language and gesture. Once the field of sign language linguistics began as an area of serious enquiry, the focus was on making sure that sign languages were credited as linguistic systems distinct from gestures produced by hearing non-signers. Prior to this point, work by scholars often presented a misleading and ignorant view of sign languages, considering them to be a primitive form of communication. Given such opinions, together with the exclusion of sign languages from deaf education and their low status in mainstream society, it is not surprising that suggested associations with gesture since that time have been met with resistance from those in the field of sign language research. It was not until the 1990s that researchers began to seriously consider the relationship between sign language and gesture (Emmorey, 1999, Liddell, 2003, Liddell, 1990, Brennan, 1992).

One area in which the issue of gesture has been most prominent is within the literature on classifier constructions in sign languages. These are signs that occupy the non-core native lexicon and are also known as classifier signs, classifier predicates, depicting signs, depicting constructions, or polymorphemic signs. The handshape identifies the class of the referent and under most analyses is considered to have a morphemic status (e.g., Supalla, 2003, Liddell, 2003). Handshapes may represent classes of objects, either partially or wholly, or the handling of objects (handling constructions). Both types of handshapes are provided in Figure 8.

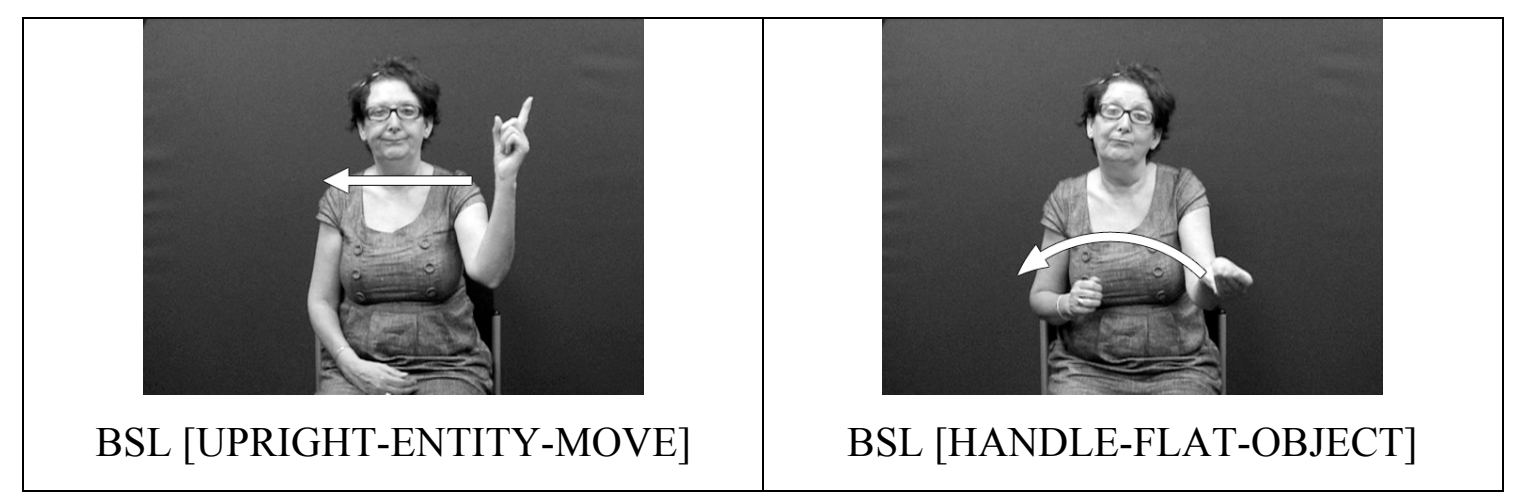


Fenlon, J., Cormier, K., \& Brentari, D. (in press). The phonology of sign languages. In S. J. Hannahs \& A. Bosch (Eds.), The Routledge Handbook of Phonological Theory: Routledge.

\begin{tabular}{|l|l|}
\hline Entity construction & Handling construction \\
\hline
\end{tabular}

Figure 8: Entity construction and handling construction (pictures from Cormier et al. 2012)

Signs from the non-core native component differ from signs within the core lexicon in that they are highly variable and weakly lexicalised. In terms of their phonology, classifier constructions do not always adhere to phonological constraints to the same extent as core, native lexical signs (Aronoff et al., 2003, Eccarius and Brentari, 2007). In addition, whilst handshapes that make up the signs within the core lexicon are argued to be purely phonological, handshapes within classifier constructions carry meaning and are considered to be additionally morphemic.

There are two opposing opinions regarding the status of these constructions: some view these constructions and all their components as part of a linguistic system that can be compared to spoken language classifier systems (Emmorey, 2003, Zwitserlood, 2012, Supalla, 2003), whilst some take the view that these constructions are different from spoken language classifier systems and include some gestural elements (Schembri, 2003, Liddell, 2003). Alternative terminologies used to refer to these forms often reflect this opinion, e.g., "depicting signs" or "depicting constructions" One argument supporting the view that classifier constructions in sign languages are unlike spoken language systems is that these forms (specifically entity and handling constructions) have much in common with observer and character viewpoint gestures respectively (Cormier et al., 2012). This similarity raises an interesting question from a phonological perspective regarding the extent to which constructions within this component demonstrate evidence of phonological patterning not seen in gesture: to what extent do the two differ?

Partly in response to this question, there has been a growth in the number of studies comparing the structure of signs by deaf signers with the gestures produced by nonsigners. One such study, using the Verbs of Motion Production task (Supalla et al., n.d.) to elicit entity constructions from Auslan signers and gestures from non-signers without speech has demonstrated that entity classifier constructions differ from gestures in that signers tend to draw upon a smaller, more conventionalised set of handshapes to represent various entities than non-signers (Schembri et al., 2005). 
Fenlon, J., Cormier, K., \& Brentari, D. (in press). The phonology of sign languages. In S. J. Hannahs \& A. Bosch (Eds.), The Routledge Handbook of Phonological Theory: Routledge.

However, less difference was seen between signers' and non-signers' use of movement and spatial arrangement of the two hands. In a similar study, Brentari et al. (2012) investigated the use of entity (those that represent the properties of a particular object) and handling constructions (those that represent how one handles a particular object) produced by signers of ASL and Italian Sign Language and compared them to entity and handling gestures produced by non-signing Italian and English in silent gesture mode (i.e., without speech). Participants had to describe what they had seen in vignettes that displayed objects with or without an agent manipulating them. Whilst the two groups of signers and two groups of gesturers patterned similarly to one another, differences were seen between signers and gesturers. Signers displayed more finger complexity in object handshapes, whilst gesturers displayed a tendency to show more finger complexity in handling handshapes (i.e. measured in terms of selected fingers complexity). Brentari et al. suggest that whilst the gesturers attempted to directly imitate the handling handshapes they saw within the vignettes, the signers drew upon the inventory of handshapes available to them within their languages (which were less complex than the real life action of handling objects in terms of selected fingers complexity). A follow-up study analysing the productions of the use of handling and object handshapes for agentive/non-agentive events by the same sign and gesture groups found that, whilst signers do and gesturers in general do not make this distinction, more Italian gesturers were able to produce this opposition than American gesturers. This suggests that some gesturers, particularly those from cultures that are observed to gesture more frequently, can intuit how to produce this distinction under laboratory conditions (Brentari et al., 2015).

Evidence from psycholinguistic studies have demonstrated that native signers can categorically perceive contrastive handshapes within the core lexicon whilst gesturers do not (Emmorey et al., 2003). However, there is evidence to suggest that categorical perception of classifier handshapes is not restricted to signers alone. Sevcikova (2013) and Sehyr Sevcikova and Cormier (in press) demonstrate that handling handshapes for flat, rectangular objects (e.g., books) and cylindrical objects (e.g., jars) varying in aperture are perceived categorically by deaf BSL signers and hearing non-signers. Such a finding points away from a phonemic categorical distinction for handling handshapes in the non-core lexicon and towards a more conventionalised gestural system shared by deaf signers and hearing non-signers. An additional follow-up study 
Fenlon, J., Cormier, K., \& Brentari, D. (in press). The phonology of sign languages. In S. J. Hannahs \& A. Bosch (Eds.), The Routledge Handbook of Phonological Theory: Routledge.

by Sevcikova (2013) examined whether continuous variation in the size of object was categorically encoded in the production of handling constructions by deaf signers and hearing gesturers (in a co-speech condition and a silent pantomime condition). Participants were first presented with stimuli encouraging them to describe the handling of various objects differing in size and these productions were later matched with the original item by a second group of judges. Within hypothesised categories of graspable object sizes (following Goldin-Meadow et al., 2007), deaf participants judging handling constructions by other deaf signers and hearing participants judging handling constructions with speech were at chance matching items with handshapes for both object types. In contrast, hearing participants judging handling constructions produced during pantomime (gesture without speech) displayed continuous size encoding for both object types.

The results from the experimental studies mentioned above allow us to make several conclusions regarding the nature of entity and handling constructions and their relationship with gesture. The data from Schembri et al. (2005) and Brentari et al. (2012) demonstrate that signers use a more conventionalised set of handshapes than gestures. Since there are more differences in handshape than in the representation of location and movement by signers and gesturers in these constructions, Schembri et al. (2005) suggest that they are blends of a linguistically specified handshape which fuses gestural elements of location (and possibly movement) thus providing evidence for the (partly) gestural analysis of these constructions. Additionally, regarding handling constructions at least, sign-naïve participants are able to categorically perceive handshape distinctions in handling constructions and also encode and decode conventionalised handshape categories in co-speech gesture (Sevcikova, 2013). This, together with other findings from Brentari et al. (2015), indicates that signs from this component of the lexicon maintain close links with gesture.

\section{CURRENT CONTRIBUTIONS AND FUTURE RESEARCH}

In this section, we focus on current contributions to the field of sign language phonology. These contributions represent new directions within the field as they incorporate new methods and technologies to help us better understand sign language phonology. Looking back at work on sign languages since the 1960s, one can see that early research was aimed primarily at showing that phonology exists in sign 
Fenlon, J., Cormier, K., \& Brentari, D. (in press). The phonology of sign languages. In S. J. Hannahs \& A. Bosch (Eds.), The Routledge Handbook of Phonological Theory: Routledge.

languages (e.g., Stokoe, 1960, Klima and Bellugi, 1979) and that units compatible with spoken languages can be identified and organised in a similar way within phonological models (as outlined in Section 3.1). Whilst these works represent significant advances within the field, there remains much to be uncovered. In this section, we present recent research on understudied sign languages, sign language corpora, approaches using instrumented capture, and gesture research which have the potential to further illuminate our understanding of the field. The studies referred to here are not intended to be exhaustive but are presented to the reader as an example of how the field can benefit from these directions in future.

\subsection{Documentation of sign languages}

Earlier work on sign language phonology sometimes worked on the assumption that an insight from one sign language was likely true for all other sign languages. Indeed, cross-linguistically, it is easy to see that are many similarities across sign languages in phonological structure. For example, the Selected Fingers Constraint appears to hold generally for sign languages. However, much of the published research on sign languages has focused on languages based in North America and Northern Europe. Our understanding of phonological structure can benefit from insights gained from other sign languages that have not been well studied to date. For example, work including sign languages in Asia has extended representations within phonological models to account for a wider range of handshapes. As noted above, phonological models to date have made a distinction between selected fingers and unselected fingers in a given sign. Selected fingers refer to the fingers that appear to be foregrounded and, for signs with handshape change, can change position within a sign (e.g., in BSL AFTERNOON and ASL THROW, the index and the middle finger are the selected fingers). Cross-linguistic research, particularly from Asian sign languages (Eccarius, 2008, Eccarius, 2002, Fischer and Dong, 2010), has revealed that, whilst this distinction is sufficient for capturing the majority of contrasts in sign languages, a further distinction needs to be made along the lines of primary selected fingers (SF1) and secondary selected fingers (SF2), along with unselected fingers (-SF). Some examples of handshapes from Hong Kong Sign Language (HKSL) illustrating this point are provided in Figure 9. The distinction between primary and secondary selected fingers has since been incorporated in recent representations of the Prosodic Model (Eccarius, 2002). 


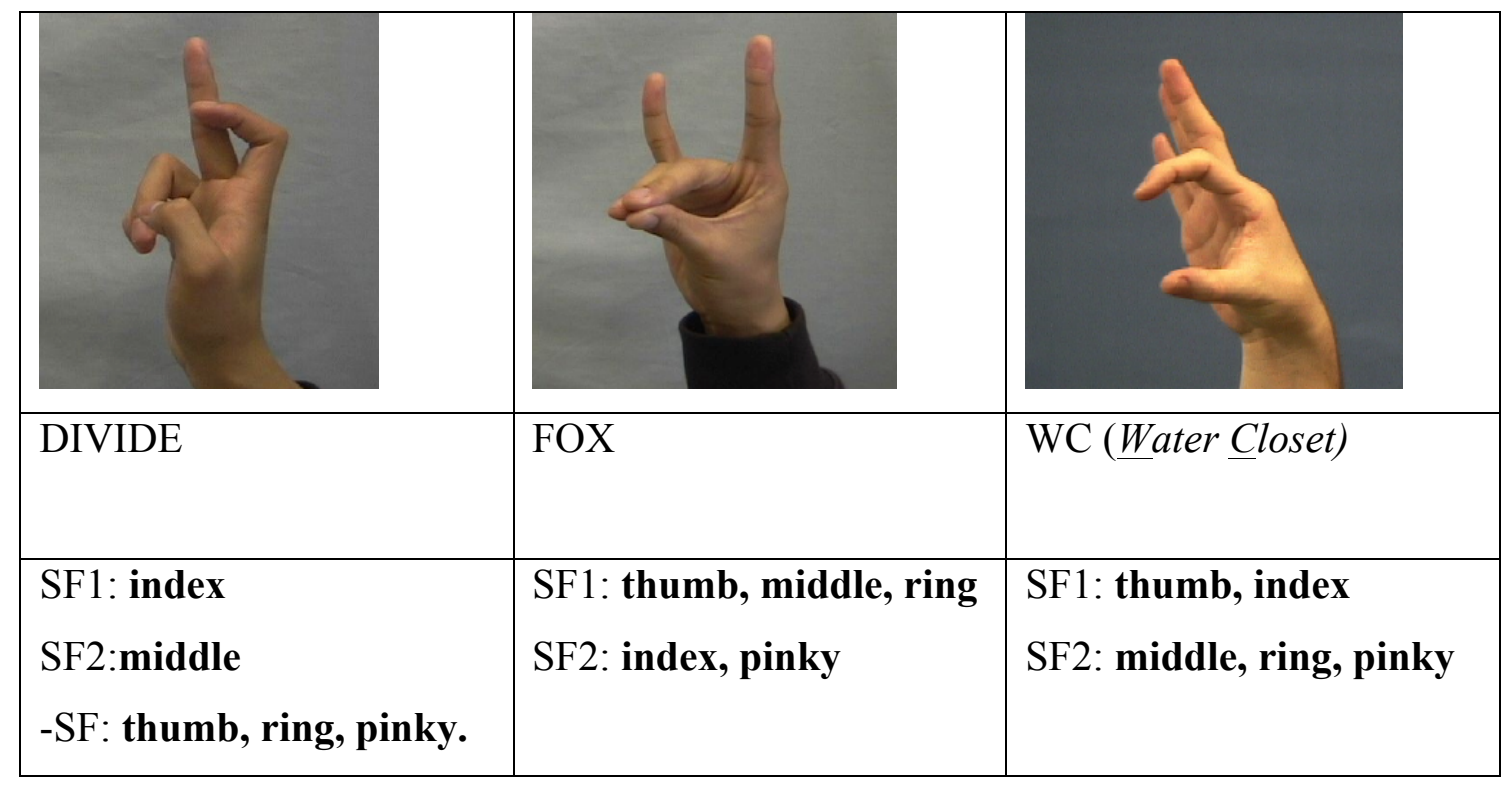

Figure 9: Sets of complex handshapes in HKSL displaying primary selected fingers, (SF1), secondary selected fingers (SF2), as well as unselected fingers (-SF)

In recent years, more and more work has been conducted on younger sign languages (although it must be said that ASL and BSL can still be described as young languages when compared to spoken languages). This type of research is important for determining how phonology appears in the early stages. In other words, what aspects of a sign are complex at first and become simple over time; what aspects do the reverse? Examples of this type of work can be found in Morgan and Mayberry (2012) where the complexity of two-handed signs is investigated in Kenyan Sign Language with reference to the Symmetry and Dominance Constraint and in Sandler et al. (2005) where the emergence of phonological structure is charted in Al-Sayyid Bedouin Sign Language (ABSL). Both Kenyan Sign Language and ABSL are relatively young, neither more than 75 years old. Data from younger sign languages like this may also contribute to issues of debate within various phonological models. For example, the data from Morgan and Mayberry (2012) appear to support a united view of the dual role of the non-dominant hand in phonological representations (as in the Prosodic and Dependency Models) since exceptional signs are better accounted for when complexity is calculated by taking features of both hands into account each time. In conclusion, it stands to reason that further research on the world's sign languages and their respective lexicons have the potential to extend existing 
Fenlon, J., Cormier, K., \& Brentari, D. (in press). The phonology of sign languages. In S. J. Hannahs \& A. Bosch (Eds.), The Routledge Handbook of Phonological Theory: Routledge.

representations so that they may better account for the full range of variability in the world's sign languages.

\subsection{Studies using sign language corpora}

In recent years, there has been a growth in the number of sign language corpus projects world-wide (e.g., in Australia, the Netherlands, Poland, Sweden, and the United Kingdom). Such corpora are designed to be large machine-readable datasets of semi-spontaneous data and representative, as far as is possible, of the deaf community. Once annotated, these corpora can provide us with a unique snapshot of sign language phonology in action across a wide range of social groups, something that has not been possible before. Usage-based studies utilising large datasets including corpora have already investigated some linguistic and social factors that condition phonological variation in sign languages. For example, two sociolinguistic studies, one focusing on BSL (Fenlon et al., 2013) and another on ASL (Bayley et al., 2002), investigated variation in the 1-handshape, a very common handshape used in lexical signs as well as pointing signs such as pronouns, and found that handshape assimilation was conditioned by grammatical category (lexical signs were more likely to preserve handshape; pronominal signs were least likely to do so) and the immediate phonological environment (preceding signs with different handshapes were more likely to assimilate to the target sign). The BSL study reported that the immediate phonological environment was the strongest factor conditioning variation whilst the ASL study reported grammatical category as the strongest predictor of handshape variation. Similar insights have been made regarding location variation in signs produced on the forehead (e.g., signs similar to BSL NAME) in ASL (Lucas et al., 2002) and Auslan and New Zealand Sign Language (Schembri et al., 2009). These variation studies not only indicate language-specific differences at play but that, in the case of the Auslan study, this variation may be indicative of a change in progress (e.g., the lowering of signs produced on the forehead appears to represent language change in progress led by younger female signers from urban centres). Such studies based on large datasets therefore afford us a strong empirical basis from which observations on phonological change can be made.

Work on sign language corpora has also highlighted the need for lexical databases that are representative of the sign language lexicon since such resources are required 
Fenlon, J., Cormier, K., \& Brentari, D. (in press). The phonology of sign languages. In S. J. Hannahs \& A. Bosch (Eds.), The Routledge Handbook of Phonological Theory: Routledge.

to assist with the process of annotation. Databases that have emerged from such projects may include a phonological description of a sign's citation form with each entry (e.g., BSL SignBank (Fenlon et al., 2014)). What this means is, as these resources grow over time to become representative of a sign language's lexicon, we will be in a position to make more accurate generalisations regarding the distribution of phonological properties in these sign languages (e.g., regarding the frequency of handshapes). Previously, even for well-researched languages, such resources have not been available. The association with a sign's occurrence in a corpus of semispontaneous data also means that researchers will be able to quickly retrieve tokens of a specific sign to better understand its use and representation in connected signing.

\subsection{Sign language and phonetic instrumentation}

As with spoken languages, a thorough understanding of phonology relies on understanding phonetics. The techniques of phonetic instrumentation with sign languages is one area in which there are still considerable advances to be made. Currently, there is no spectrographic analysis for sign language and most phonetic transcriptions are still done manually with the naked eye (e.g., many researchers use programs like ELAN (http://www.tla.mpi.nl/tools/tla-tools/elan/) to code data manually). As a result, the field of sign language phonetics is often described as an area in which little progress has been made. In recent years however, there has been a growth in the number of studies using motion capture in order to understand exactly how the production of signs vary in terms of its kinetic properties. Earlier work incorporating this type of technique can be traced to the 1990s. For example, one study by Wilbur and Zelaznik (1997) investigated how duration and velocity are distributed with respect to prosodic phrasing using a 3-D motion analyser system (WATSMART) and found that duration marks final phrase position and that velocity marks prominence.

Other studies which have used motion capture include Cheek (2001) to investigate pinky extension in handshape, Malaia and Wilbur (2011) in their study of ASL verbs with regards to telicity, and Mauk and Tyrone (2012) in investigating location variation in ASL signs produced at the forehead. These studies provide us with further insights into the factors that affect a sign's production using a more fine-grained analysis and in some cases building on conclusions from studies using corpora. For 
Fenlon, J., Cormier, K., \& Brentari, D. (in press). The phonology of sign languages. In S. J. Hannahs \& A. Bosch (Eds.), The Routledge Handbook of Phonological Theory: Routledge.

example, whilst the immediate phonological environment has been identified as an important predictor in handshape assimilation in the corpus-based studies above, Cheek (2001) investigating handshape variation found an effect of phonetic environment which was rate dependent; such a finding suggests that coarticulation effects (rather than assimilation) are at play. Similarly, Tyrone and Mauk (2010), using motion capture data, found signing rate to be a significant predictor of sign lowering although this was not uniform for all signs; for some signs, there was an interaction with the phonetic environment. In Mauk and Tyrone (2012), a more detailed analysis (again focusing on signs produced on the forehead) took into account the phonetic location of the preceding and following signs and found that the direction of coarticulation was strongest with the following sign (i.e., as the location value of the following sign moved up the vertical axis, so too did the location value of the target sign ASL KNOW). Additionally, the authors demonstrate that it is not only the hands that move but that passive articulators, the forehead in this case, can play a role. In other words, when producing ASL KNOW, the forehead may move to meet the hand; this type of movement was observed at slower signing rates in ASL. Furthermore, Mauk and Tyrone (2012) found that native signers appear to be more compact in their use of signing space when compared to non-native signers which, in turn, may require them to make more subtle phonological contrasts with respect to the location parameter. Importantly, such studies demonstrate that instrumented capture affords us a better insight regarding the complex array of factors that characterise variation than categorical measures (in particular, coding systems that rely solely on the naked eye).

\section{CONCLUSION}

To conclude, we have described some of the most important areas of research in sign language phonology both historically and currently. At the end of a chapter such as this one, we would like to offer two reasons why phonologists who conduct research on spoken languages should care about the phonology of sign languages. The first has to do with work concerning sign language and gesture, some of which was discussed in Section 3.3, which is becoming increasingly important in understanding human language. Spoken languages clearly include both speech and the gestures that accompany them as co-speech gesture. There are numerous researchers that have 
Fenlon, J., Cormier, K., \& Brentari, D. (in press). The phonology of sign languages. In S. J. Hannahs \& A. Bosch (Eds.), The Routledge Handbook of Phonological Theory: Routledge.

made this claim in psychology, most notably Goldin-Meadow (2003) and McNeill (1992), and they have described many ways that gestures contribute to the meaning of our utterances in a variety of ways. Pinpointing work that is relevant for a volume on phonology, work by Krahmer and Swerts (2007) have opened up a field of inquiry describing the ways that beat gestures, which co-occur with the prominent syllable of a phonological phrase, can influence how we perceive the vocal prominence of the prominent syllable. Assuming this body of work continues to gain support, analyses on spoken languages, particularly on spoken language prosody, will routinely include properties of the face and body and will be bi-modal. The insights from work on sign languages where the body is a site for phonological operations such as the syllable will potentially be of great use in that work. The sign language syllable, in particular, offers tools for how to think about the componentiality of gesture in this new area of inquiry that couples gesture with speech in considering the totality of spoken language.

The second reason why phonologists who study spoken languages should be concerned with sign language phonology constitutes the ultimate goal of our work as a whole: namely, to describe the full range of extant phonological systems and to strive to construct theories that can handle both. Hale and Reiss (2008) have gone so far as to propose that the work of describing "substance-free" phonology is the primary task of phonologists. Although we are still a very long way from achieving that goal, nonetheless we are optimistic. As Stephen Anderson (1989:803) wrote, "[Phonology] is a domain of human cognition where we probably know more in detail about the specific principles operative within a particular cognitive subsystem than anywhere else, and about the specific representations that play a part in such knowledge." Sign languages are much more than a couple of extra data points on the landscape of possible phonological systems, or a new quirky set of facts that stretch current theory. They are a set of languages with long histories which have generated solutions to building efficient and effective phonological systems with some materials that are the same as those of speech (the same mind/brain) and some different ones. It is the resilient creativity in response to our human need to communicate that gave rise to the range of phonological structures in sign languages. Working on how signed and spoken languages can genuinely be handled by the same phonological tools gets us 
Fenlon, J., Cormier, K., \& Brentari, D. (in press). The phonology of sign languages. In S. J. Hannahs \& A. Bosch (Eds.), The Routledge Handbook of Phonological Theory: Routledge.

ever closer to understanding phonology, generally speaking, and for this reason this chapter is written for everyone in the field.

Word count: 11,225 (including references)

\section{Further reading}

BATTISON, R. 1978. Lexical Borrowing in American Sign Language, Silver Spring, Linstok Press. This text delivers a good overview of the subject area as well as a description of phonological processes observed in fingerspelled loan signs.

BRENTARI, D. 1998. A Prosodic Model of Sign Language Phonology, Cambridge, Massachusetts, MIT Press. We recommend this text for those seeking a detailed description of the Prosodic Model as well as background on sign language phonology.

LIDDELL, S. K. \& JOHNSON, R. E. 1989. American Sign Language: the phonological base. Sign Language Studies, 64, 195-278. This paper introduces the Hold-Movement model mentioned in Section 3.1.

SANDLER, W. \& LILLO-MARTIN, D. 2006. Sign Language and Linguistic Universals, Cambridge, Cambridge University Press. This textbook provides a detailed overview of sign language phonology across several chapters focusing on the Hand-Tier Model.

STOKOE, W. 1960. Sign language structure: an outline of the visual communication system of the American Deaf. Studies in Linguistics Occasional Paper 8. University of Buffalo. Stokoe's seminal paper remains a must for anyone interested in sign language phonology.

\section{Acknowledgements}

This work was supported by funding from the Economic and Social Research Council of Great Britain (Grant RES-620-28-0002), Deafness, Cognition and Language Research Centre (DCAL), from the National Science Foundation (BCS-1227908 to D.B.), and from the Neubauer Collegium for Culture and Society at the University of Chicago. We thank Sandra Smith for acting as a model in Figure 8. The stills provided in Figure 2 are from BSL SignBank (Fenlon et al., 2014).

Related topics: [None to suggest] 
Fenlon, J., Cormier, K., \& Brentari, D. (in press). The phonology of sign languages. In S. J. Hannahs \& A. Bosch (Eds.), The Routledge Handbook of Phonological Theory: Routledge.

\section{REFERENCES}

ANDERSON, J. \& EWEN, C. J. 1987. Principles of Dependency Phonology, Cambridge, Cambridge University Press.

ANDERSON, S. 1989. The computer and the mind: An introduction to cognitive science by Philip N. Johnson-Laird [Review]. Language, 65, 800-811.

ARONOFF, M., MEIR, I., PADDEN, C. \& SANDLER, W. 2003. Classifier constructions and morphology in two sign languages. In: EMMOREY, K. (ed.) Perspectives on classifier constructions in sign languages. Mahwah, New Jersey: Lawerence Erlbaum Associates.

BATTISON, R. 1978. Lexical borrowing in American Sign Language, Silver Spring, MD, Linstock Press.

BAYLEY, R., LUCAS, C. \& ROSE, M. 2002. Phonological variation in American Sign Language: The case of 1 handshape. Language Variation and Change, 14, 19-53.

BELLUGI, U. \& FISCHER, S. 1972. A comparison of sign language and spoken language. Cognition, 1, 173-200.

BLOOMFIELD, L. 1933. Language, New York, Holt.

BREGMAN, A. S. 1990. Auditory Scene Analysis: The Perceptual Organisation of Sound, MA, MIT Press.

BRENNAN, M. 1992. The Visual World of British Sign Language: An Introduction. In: BRIEN, D. (ed.) Dictionary of British Sign Language/English. Faber and Faber.

BRENTARI, D. 1990. Licensing in ASL handshape change. In: LUCAS, C. (ed.) Sign Language Research: Theoretical Issues. Washington, DC: Gallaudet University Press.

BRENTARI, D. 1993. Establishing a sonority hierarchy in American Sign Language: The use of simultaneous structure in phonology. Phonology, 10, 281-306.

BRENTARI, D. 1998. A prosodic model of sign language phonology, Cambridge, MA, MIT Press.

BRENTARI, D. 2002. Modality differences in sign langauge and phonology and morphophonemics. In: MEIER, R. P., QUINTO-POZOS, D. \& CORMIER, K. (eds.) Modality and Structure in Signed and Spoken Languages. Cambridge: Cambridge University Press.

BRENTARI, D. 2012. Phonology. In: PFAU, R., STEINBACH, M. \& WOLL, B. (eds.) Sign Language: An International Handbook. Berlin, Germany: Mouton de Gruyter.

BRENTARI, D., COPPOLA, M., MAZZONI, L. \& GOLDIN-MEADOW, S. 2012. When does a system become phonological? Handshape production in gesturers, signers, and homesigners. Natural Language and Linguistic Theory, 30, 1-31.

BRENTARI, D., DI RENZO, A., KEANE, J. \& VOLTERRA, V. 2015. Cognitive, cultural, and linguistic sources of a handshape distinction expressing agentivity. TopiCS, 7, 1-29.

BRENTARI, D. \& PADDEN, C. 2001. Native and foreign vocabulary in American Sign Language: a lexicon with multiple origins. In: BRENTARI, D. (ed.) Foreign vocabulary in sign languages. Mahwah, New Jersey: Lawrence Erlbaum Associates.

CHANNON, R. 2002. Beads on a string? Representations of repetition in spoken and signed languages. In: MEIER, R. P., QUINTO-POZOS, D. \& CORMIER, K. 
(eds.) Modality and Structure in Signed and Spoken Languages. Cambridge: Cambridge University Press.

CHANNON, R. \& VAN DER HULST, H. 2011. Are dynamic features required in signs? In: CHANNON, R. \& VAN DER HULST, H. (eds.) Formational units in sign languages. Berlin: Mouton de Gruyter.

CHASE, C. \& JENNER, A. R. 1993. Magnocellular visual deficits affect temporal processing of dyslexics. Annals of the New York Academy of Sciences, 682, 326-329.

CHEEK, A. D. 2001. The phonetics and phonology of handshape in American Sign Language. $\mathrm{PhD}$, University of Texas at Austin.

CHOMSKY, N. \& HALLE, M. 1968. The sound pattern of English, New York, Harper and Row.

CORINA, D. 1990. Reassessing the role of sonority in syllable structure: Evidence from a visual-gestural language. Papers from the 26th Annual meeting of the Chicago Linguistic Society: Vol 2: Parasession on the syllable in phonetics and phonology. Chicago, Illinois: Chicago Linguistic Society, University of Chicago.

CORMIER, K., QUINTO-POZOS, D., SEVCIKOVA, Z. \& SCHEMBRI, A. 2012. Lexicalisation and de-lexicalisation processes in sign languages: Comparing depicting constructions and viewpoint gestures. Lang Commun, 32, 329-348.

CRASBORN, O. \& VAN DER KOOIJ, E. 1997. Relative orientation in sign language phonology. In: COERTS, J. \& HOOP, H. D. (eds.) Linguistics in the Netherlands 1997. Amsterdam: John Benjamins Publishing Company.

ECCARIUS, P. 2002. Finding common ground: A comparison of handshape across multiple sign languages. MA, Purdue University.

ECCARIUS, P. 2008. A constraint-based account of handshape contrast in sign languages. $\mathrm{PhD}$, Purdue University.

ECCARIUS, P. \& BRENTARI, D. 2007. Symmetry and dominance: a cross-linguistic study of signs and classifier constructions. Lingua, 117, 1169-1201.

EMMOREY, K. 1999. Do signers gesture? In: MESSING, L. S. \& CAMPBELL, R. (eds.) Gesture, speech, and sign. Oxford: Oxford University Press.

EMMOREY, K. 2003. Perspectives on classifier constructions, Mahwah, NJ, Lawrence Erlbaum Associates.

EMMOREY, K., MCCUllough, S. \& BRENTARI, D. 2003. Categorical perception in American Sign Language. Language and Cognitive Processes, $18,21-45$.

FENLON, J., CORMIER, K., RENTELIS, R., SCHEMBRI, A., ROWLEY, K., ADAM, R. \& WOLL, B. 2014. BSL SignBank: A lexical database of British Sign Language (First Edition), London, Deafness, Cognition and Language Ressearch Centre, University College London.

FENLON, J., SCHEMBRI, A., RENTELIS, R. \& CORMIER, K. 2013. Variation in handshape and orientation in British Sign Language: The case of the ' 1 ' hand configuration. Language and Communication, 33, 69-91.

FISCHER, S. \& DONG, Q. 2010. Variation in East Asian sign language structures. In: BRENTARI, D. (ed.) Sign Languages: A Cambridge Language Survey. Cambridge: Cambridge University Press.

GERACI, C. 2009. Epenthesis in Italian Sign Language. Sign Language \& Linguistics, $12,3-51$.

GOLDIN-MEADOW, S. 2003. Hearing gesture: How our hands help us think, Cambridge, MA, Harvard University Press. 
Fenlon, J., Cormier, K., \& Brentari, D. (in press). The phonology of sign languages. In S. J. Hannahs \& A. Bosch (Eds.), The Routledge Handbook of Phonological Theory: Routledge.

GOLDIN-MEADOW, S., MYLANDER, C. \& FRANKLIN, A. 2007. How children make language out of gesture: Morphological structure in gesture systems developed by American and Chinese deaf children. Cognitive Psychology, 55, 87-135.

GREEN, D. 1971. Temporal auditory acuity. Pschological Review, 78, 540-551.

GROSJEAN, F. 1977. The perception of rate in spoken language and sign languages. Journal of Psycholinguistic Research, 22, 408-413.

HALE, M. \& REISS, C. 2008. The Phonological Enterprise, Oxford, Oxford University Press.

JANTUNEN, T. 2007. Tavu Suomalaisessa Viittomakielessä [The syllable in Finnish Sign Language; with English abstract]. Puhe ja kieli, 27, 109-126.

JOHNSTON, T. 1989. The sign language of the Australian deaf community. Doctoral dissertation, University of Sydney.

JOHNSTON, T. \& SCHEMBRI, A. 1999. On defining lexeme in a signed language. Sign Language \& Linguistics, 2, 115-185.

KLIMA, E. \& BELLUGI, U. 1979. The Signs of Language, Cambridge, MA, Harvard University Press.

KOHLRAUSCH, A., PÜSCHEL, D. \& ALPHEI, H. 1992. Temporal resolution and modulation analysis in models of the auditory system. In: SCHOUTEN, M. E. H. (ed.) The Auditory Processing of Speech: From Sounds to Words. Berlin: Mouton de Gruyter.

KRAHMER, E. \& SWERTS, M. 2007. The effect of visual beats on prosodic prominence: Acoustic analyses, auditory perception and visual perception. Journal of Memory and Language, 57, 396-414.

LIDDELL, S. K. 1990. Four functions of a locus: Reexamining the structure of space in ASL. In: LUCAS, C. (ed.) Sign Language Research: Theoretical Issues. Washington, DC: Gallaudet University Press.

LIDDELL, S. K. 2003. Grammar, gesture and meaning in American Sign Language, Cambridge, Cambridge University Press.

LIDDELL, S. K. \& JOHNSON, R. E. 1989. American Sign Language: the phonological base. Sign Language Studies, 64, 195-278.

LUCAS, C., BAYLEY, R., ROSE, M. \& WULF, A. 2002. Location Variation in American Sign Language. Sign Language Studies, 2, 407-440.

MACNEILAGE, P. F. 2008. The Origin of Speech, Oxford, Oxford University Press.

MACNEILAGE, P. F. \& DAVIS, B. L. 1993. Motor explanations of babbling and early speech patterns. In: BOYSSON-BARDIES, B., SCHONEN, S. D., JUSCZYK, P., MACNEILAGE, P. F. \& MORTON, J. (eds.) Development Neurocognition: Speech and Face Processing in the First Year of Life. Dordrecht: Kluwer.

MALAIA, E. \& WILBUR, R. 2011. Kinematic signatures of telic and atelic events in ASL predicates. Language and Speech, 55, 407-421.

MANDEL, M. 1981. Phonotactics and morphophonology in American Sign Language, University of California.

MAUK, C. E. \& TYRONE, M. E. 2012. Location in ASL: Insights from phonetic variation. Sign Language \& Linguistics, 15, 128-146.

MCNEILL, D. 1992. Hand and mind: What gestures reveal about thought, Chicago, IL, University of Chicago Press.

MEIER, R. P. 2002. Why different, why the same? Explaining effects and non-effects of modality upon linguistic structure in sign and speech. In: MEIER, R. P., 
CORMIER, K. \& QUINTO-POZOS, D. (eds.) Modality and Structure in Signed and Spoken Languages. Cambridge: Cambridge University Press.

MEIER, R. P. 2012. Language and modality. In: PFAU, R., STEINBACH, M. \& WOLL, B. (eds.) Sign Language: An International Handbook. Berlin, Germany: Mouton de Gruyter.

MORGAN, H. \& MAYBERRY, R. 2012. Complexity in two-handed signs in Kenyan Sign Language. Sign Language \& Linguistics, 15, 147-174.

NEIDLE, C., KEGL, J., MACLAUGHLIN, D., BAHAN, B. \& LEE, R. 2000. The syntax of American Sign Language: functional categories and hierarchical structure, Cambridge, Massachusetts, MIT Press.

NESPOR, M. \& SANDLER, W. 1999. Prosody in Israeli Sign Language. Language and Speech, 42, 143-176.

PERLMUTTER, D. M. 1992. Sonority and syllable structure in American Sign Language. Linguistic Inquiry, 23, 407-442.

PETTITO, L. \& MARENTETTE, P. 1991. Babbling in the manual mode: Evidence for the ontogeny of language. Science, 25, 1493-1496.

SANDLER, W. 1989. Phonological representation of the sign: Linearity and nonlinearity in American Sign Language, Dordrecht, Foris.

SANDLER, W. 1993. A Sonority Cycle in American Sign Language. Phonology, 10, 209-241.

SANDLER, W. \& LILLO-MARTIN, D. 2006. Sign Language and Linguistic Universals, Cambridge, Cambridge University Press

SANDLER, W., MEIR, I., PADDEN, C. \& ARONOFF, M. 2005. The emergence of grammar: systematic structure in a new language. Proc Natl Acad Sci US A, 102, 2661-5.

SCHEMBRI, A. 2003. Rethinking "classifiers" in signed langauges. In: EMMOREY, K. (ed.) Perspectives on classifier constructions in sign languages. Mahwah, NJ: Lawrence Erlbaum Associates.

SCHEMBRI, A., JONES, C. \& BURNHAM, D. 2005. Comparing action gestures and classifier verbs of motion: evidence from Australian Sign Language, Taiwan Sign Language, and nonsigners' gestures without speech. Journal of Deaf Studies and Education, 10, 272-90.

SCHEMBRI, A., MCKEE, D., MCKEE, R., PIVAC, S., JOHNSTON, T. \& GOSWELL, D. 2009. Phonological variation and change in Australian and New Zealand Sign Languages: The location variable. Language Variation and Change, 21, 193.

SEHYR SEVCIKOVA, Z. \& CORMIER, K. in press. Perceptual categorization of handling handshapes in British Sign Language. Language and Cognition.

SEVCIKOVA, Z. 2013. Categorical versus gradient properties of handling handshapes in British Sign Language (BSL). PhD, University College London.

SIPLE, P. 1978. Visual constraints for sign language communication. Sign language Studies, 19, 95-110.

STOKOE, W. 1960. Sign language structure: an outline of the visual communication system of the American Deaf. Studies in Linguistics Occasional Paper 8. University of Buffalo.

STOKOE, W., CASTERLINE, D. C. \& CRONEBERG, C. G. 1965. A Dictionary of American Sign Language on Linguistic Principles, Linstok Press.

SUPALLA, T. 2003. Revisiting visual analogy in ASL classifier predicates. In: EMMOREY, K. (ed.) Perspectives on classifier constructions in sign languages. Mahwah, NJ. 
SUPALLA, T., NEWPORT, E. L., SINGLETON, J., SUPALLA, S., METLAY, D. \& COULTER, G. n.d. The Test Battery for American Sign language Morphology and Syntax. University of Rochester, New York.

TYRONE, M. E. \& MAUK, C. E. 2010. Sign lowering and phonetic reduction in American Sign Language. Journal of Phonetics, 38, 317-328.

UYECHI, L. 1995. The Geometry of Visual Phonology. PhD, Stanford University.

VAN DER HULST, H. 1993. Units in the analysis of signs. Phonology, 10, 209-241.

VAN DER KOOIJ, E. 2002. Phonological categories in Sign Language of the Netherlands: the role of phonetic implementation and iconicity. $\mathrm{PhD}$ dissertation, Leiden University.

WILBUR, R. \& ZELAZNIK, H. N. Kinematic correlates of stress and position in ASL. Linguistic Society of America, 1997 Chicago. Illinois.

ZESHAN, U. 2004. Interrogative constructions in signed languages: Crosslinguistic perspectives. Language, 80, 7-39.

ZWITSERLOOD, I. 2012. Classifiers. In: PFAU, R., STEINBACH, M. \& WOLL, B. (eds.) Sign language: An international handbook. Berlin: Mouton de Gruyter. 